\title{
INTRODUÇÃO
}

Marisol de la Cadena

Jorge Legoas $P$.

\section{COSMOPOLÍTICA NOS ANDES E NA AMAZÔNIA: COMO POLÍTICAS INDÍGENAS AFETAM A POLÍTICA?}

Ya está bueno! Estas personas no tienen corona, estas personas no son ciudadanos de primera clase que puedan decir-400 mil nativos a 28 millones de peruanos- “tú no tienes derecho de venir por aquí”. De ninguna manera! Eso es un error gravísimo y quien piense de esa manera quiere llevarnos a la irracionalidad y al retroceso primitivo en el pasado (Alan García, Presidente do Peru, 05 de junho de 2009).

¿Es obligatorio sacar gas y petróleo del norte amazónico de La Paz? Sí. ¿Por qué? Porque necesitamos equilibrar las estructuras económicas de la sociedad boliviana (...). Junto al derecho a la tierra de un pueblo está el derecho del Estado, del Estado conducido por el movimiento indígena-popular y campesino, de sobreponer el interés colectivo mayor de todos los pueblos. Yasí vamos a proceder hacia delante. (Álvaro García Linera, Vice-Presidenet da Bolívia, 01 de setembro de 2009).

[Es] absurdo [el] paro antiminero, porque son posiciones intransigentes, irracionales, con eso no se puede conversar (...) Hay que ser responsables, no podemos vivir como mendigos sentados en un saco de oro; no podemos, por fundamentalismos, sacrificar el bienestar del país. (Rafael Correa, Presidente do Equador, 24 de janeiro de 2009).

Este dossiê discute as práticas indígenas enquanto que ocupam esferas da vida moderna. Eles apresentam a diferença radical das práticas indígenas quando emergem em circunstâncias em que aqueles que não participam da radical diferença compartilham. A diferença que apresentam é radical porque surge de circunstâncias que não se conformam em divisões que separam a humanidade e seus outros (cultura e natureza, o animado e o inanimado, material eespiritual) enormatizam o entendimento da vida moderna. Em vez de dividir a norma, nestes artigos, montanhas são seres, sucuris são ancestrais, uma faca comunica, corpos (humanos e animais) resultam do que fazem (incluso o que comem), água se recusa a ser $\mathrm{H} 2 \mathrm{O}$. Assim, quando os artigos focam as práticas indígenas em vez de etnicidade, ou raça (as categorias usuais de análise da 'alteridade'), assumem um caminho analítico, pois ambos os conceitos tomariam apenas humanos como protagonistas. Focalizando em diferenças entre humanos, seriam incapazes de incluir entidades as outras que não humanas como agentes das práticas indígenas que os trabalhos desta edição apresentam. 
A diferença que estes artigos exploram escapa de categorias que trabalham para explicar diferenças de dentro de um mundo compartilhado: isto é, o mundo que resulta da divisão entre humanos como agentes ou sujeitos agindo sobre objetos considerados desprovidos de agência, usualmente chamados de natureza. Essa relação pode ser de conhecimento (se articulada através da ciência) ou crença (se articulada através de práticas identificadas como religiosas, supersticiosas, espirituais, mágicas, entre outras). Dado que nas histórias hegemônicas (ainda vale dizer), o conhecimento supera a crença. A hegemonia dessa vitória (que não é necessária para que a ciência seja significativa) tem como sua condição onto-epistêmica uma noção da 'realidade lá fora'. E essa condição é onto-epistêmica porque é uma noção de constituição de mundo que simultaneamente enquadra as condições de seu entendimento por conhecimento ou por crença. Essa 'realidade lá fora' é chamada de natureza, tida como em espera por aqueles que habitam a cultura para interpretá-la (Law 2004, Viveiros de Castro 2004). Desse modo, a diferença que estes artigos exploram é radical em relação à raça, etnicidade, cultura ou natureza (e seus cognatos): essas categorias são insuficientes para narrar tal diferença sem reduzi-la a eventos unicamente entre pessoas - e um tipo específico de pessoas: aqueles que marcam a diferença pelo centro. E esse centro é inabitado, por exemplo (e baseado no artigo de Cayón), aqueles tão radicalmente diferentes das sucuris que não poderiam possivelmente descender delas. Ou aqueles que não conseguem entender a possibilidade de serem aquilo que comem ou o que fazem, como os amigos Ashaninka de Juan Pablo Sarmiento. Ou aqueles que participaram na escritura da constituição boliviana se sentirem absolutamente desconfortáveis com a ideia da Pachamama - traduzida como terra cultivável (uma categoria econômica) e Mãe Terra (entidade religiosa) - como um ser.

Um aspecto saliente comum entre estes trabalhos é que muitas das práticas que descrevem não se conformam pela divisão entre natureza e cultura; um segundo aspecto é que tampouco pode ser dito que essas práticas ordenam um 'mundo indígena' homogêneo. Antes, elas ordenam mundos diferentes, onde diferenças e similaridades entre entidades são distribuídas em seu próprio e distinto modo. O terceiro aspecto, que pode parecer contraintuitivo: apesar das radicais diferenças com o mundo ordenado pela divisão natureza-cultura, as práticas aqui descritas são ordenadas também em conexão com ele. Assim, a total contemporaneidade delas é tão inegável quanto a diferença que transpõe o entendimento do mundo moderno. O que nos leva à congruência final destes artigos: como uma coleção, eles tomam parte de uma conceitualização de indigeneidade como formação histórica que existe em uma relação de 'conexão parcial' com as instituições estado-nação latino-americanas. "Conexão parcial”, um conceito que pegamos emprestado de Marilyn Strathern, refere-se a uma relação compondo um agregado que é "nem singular nem plural, nem um nem muitos; antes um circuito de conexões do que partes unidas" (Strathern 2004:54). Conexões parciais criam não uma única entidade; a entidade que resulta é mais que uma, mas ainda menos que duas. As 'fronteiras' entre aquelas assim conectadas são complexas. Elas (as fronteiras) existem como uma relação histórica simbiótica entre as áreas (e as práticas) da vida que elas separam, assim também ordenando uma conexão entre elas. Nenhuma parte da vida é sem as outras, mas não são uma unidade, nem mesmo uma unidade diferenciada. Elas compartilham histórias, calendários, identidades, práticas; mas também são diferentes em maneiras em que as outras nem mesmo podem participar. Consequentemente-e até obviamente-compartilharam situações (e as fronteiras e práticas que as formam) que afetam essas áreas da vida parcialmente conectadas de forma diferenciada. 
Enquanto campos parcialmente conectados da vida, e compartilhando a esfera do estado-nação, as formações indígenas descritas nestes artigos participam na política moderna. Frequentemente elas participam em movimentos sociais sob a bandeira dos direitos étnicos de vida e contra modelos hegemônicos que priorizam o crescimento econômico (Ramos \& Sabatella, Salas, Sarmiento), mas às vezes elas podem também estar envolvidas nas práticas hegemônicas (Cayón, Schavelzon, Martínez). Nisso, recebem apoio e aliança de ambientalistas, organizações de direitos humanos, organizações não governamentais de esquerda, e intelectuais; também participam em práticas governamentais. Mas o apoio das ONGs e a participação no governo têm seus limites - e os limites são colocados pelo que a política moderna pode reconhecer; na sua manifestação mais benevolente, esses limites são representados como uma expressão do comando do Estado em busca do bem comum. O segundo discurso de abertura do reeleito Vice Presidente da Bolívia, Álvaro García Linera, socialista autodeclarado, manifesta exatamente esses limites: direitos indígenas existem contingentes ao bem comum - eles são também o limite da tolerância do antigo Presidente neoliberal do Peru, Alan García. A divergência ideológica entre os dois governantes termina no mesmo ponto onde sua tolerância aos direitos indígenas também termina, trespassada pelo que julgam ser a obrigação do Estado por desenvolvimento e crescimento econômico. E esse ponto, onde a tolerância da política moderna termina, é também o ponto onde um tipo diferente de política começa: um que revela a discordância fundamental que emerge da diferença ontológica, com o que queremos dizer aquelas práticas que afastam mundos simbioticamente, isto é, enquanto elas fazem a si mesmas em relação com as outras. A divergência então é parcialmente conectada, e assim complexa - assim como é a política que transparece através dessa complexidade. É essa uma política que afirma a multiplicidade de mundos, e assim fazendo revela que a negação moderna corresponde a uma vontade de destruição - a questão principal então é: encolhemos os ombros em face desta vontade, e continuamos a declarar um mundo igualitário que não o é, e não será como tal? Ou encaramos a complexidade dos mundos parcialmente conectados e seguimos as políticas indígenas enquanto elas mostram-se em acordo com essa complexidade? Os artigos desta edição adotam a segunda questão. Mas antes que expliquemos como o fazem, uma apresentação de nossa proposta conceitual é necessária.

\section{DISCORDÂNCIA OU UMA POLÍTICA DENTRE MUNDOS NOS ANDES E NA AMAZÔNIA: COMO POLÍTICAS INDÍGENAS AFETAM A POLÍTICA?}

Nosso título “como as políticas indígenas afetam a política?” tem a intenção de explorar, e esperançosamente adicionar algo a, um problema que Bruno Latour propôs quando discorrendo sobre Boyles e Hobbes. O primeiro desenvolveu a ciência experimental, e o segundo, a política; contudo, seu trabalho, diz Latour, por fim convergiu em uma grande convenção. Eles eram como "dois pais fundadores, agindo em harmonia para promover uma só e mesma inovação na teoria política: à ciência recai a representação de não humanos, mas lhes é interdita toda possibilidade de apelo à política; à política recai a representação dos cidadãos, mas ela é interdita de ter uma relação qualquer com os não humanos produtos e mobilizados pela ciência e a tecnologia"(Latour 1991:44). Se o liberalismo ligou a política à ética e, assim, negou o conflito, e o socialismo enfatizou o conflito (na versão marxista, luta de classes) essa diferença estava ligada ao acordo sobre a distinção ontológica entre "Humanidade" e "Natureza" que foi fundamental ao nascimento do campo da política moderna-e que até recentemente foi identificado como teoria política. 
Seguindo essa ideia (proposta também por Haraway, 1991) nós conceitualizamos essa distinção como ordenadora e ordenada pelo que Latour chamou de Constituição Moderna. Como um regime epistêmico fundamental, essa constituição articula a noção de política como a herdamos: organização e regulação de pessoas em estados (e suas práticas derivadas: governos, parlamentos, instituições legais, partidos políticos), que, juntamente com a esfera da natureza, formam o mundo como o conhecemos, i.e., como um e, quer queira quer não, compartilhado. A divisão entre uma natureza e uma-ainda-que-diversa humanidade também permitiu a criação do 'homem natural' sentenciado à extinção inevitável junto com seus outros seres não humanos. $\mathrm{O}$ campo da política que atualmente reconhecemos como tal foi formado por não somente a distinção entre amigos e inimigos entre os humanos - Como Carl Schmitt (1996) propôs; como também requereu a separação antitética entre "humanidade" e "natureza": quanto mais se tem de um, menos se tem do outro, e isso organizou o mundo em um unificado espaço hierárquico. Juntas, essas duas antíteses - entre humanidade e natureza, e entre pessoas alegadamente superiores ou inferiores - declararam a gradual extinção de seres outros-que-não-humanos e os mundos nos quais eles existiram. A antítese epistêmica teve sua contrapartida empírica na destruição dos assim chamados povos indígenas, acompanhada por uma "humanidade" inflexivelmente inclusiva e hierarquicamente organizada. Uma vez a destruição antagônica obscurecida, apenas os completamente humanos engajados em antagonismos, e apenas eles, poderiam transformar suas inimizades em relações antagônicas - isto é, se engajar na política.

Inicialmente, o antagonismo entre universalizar europeus e entidades outras-que-não-humanas - nos termos de Schmitt, a guerra entre inimigos - era visível. Na América hispânica, a Igreja Católica considerava essas entidades como inimigos diabólicos, práticas com seres da terra eram idolatrias condenadas ao extermínio. NaAmérica britânica, Locke autorizou guerra aos nativos: sua proximidade com a natureza os fazia improdutivos, e a terra precisava ser incorporadaà civilização por meio do trabalho da agricultura do homem branco. O antagonismo deve ter sido silenciado gradualmente ao que a razão ganhou força e eventualmente prevaleceu sobre a fé enquanto regime de conhecimento/ poder, e monopolizou a política para aqueles que ‘sabiam' através de ciência. Interações com as coisas através de práticas não representacionais - a ausência de distinção entre significante e significado que permitiu à prática da ciência moderna políticas similares - foram consideradas equivalentes à ausência de racionalidade, e mais especificamente de racionalidade política. Em tal campo de batalha - dominado pela razão - decisões foram tomadas sobre quem são os inimigos, mas, tão importante como, quem, não suportando o antagonismo, não é merecedor nem mesmo do status de inimigo. Em ocasiões em que eles não são ao menos dignos de matar, podem ser deixados para morrer porque, embora incluídos no conceito de "humanidade", eles não contam - completamente, pois que eles carecem de racionalidade e, portanto, estão próximos demais da "natureza" (assim tornando o antagonismo sem sentido).

O mundo ocidental definiu sua missão colonial como civilizatória, e acumulou poder hegemônico para homogeneizar a humanidade de acordo com sua própria relação com a natureza. Nessa narrativa, a relação entre mundos distintos era de guerra - em muitos casos, hegemônica o suficiente para evitar seu reconhecimento como 
tal. Sua aparência de exagero - caso assim soe para alguns leitores - apenas reflete a continuada hegemonia do Constituição Moderna, seu direito de reger as pessoas que se opõem à divisão que ela continua a ordenar. Políticas como uma relação de discordância dentre mundos - nas palavras de Rancière (1999:42) surgindo de "encontros entre heterogêneos" públicos (ibid, 1999:32) - não possuem espaço nesta constituição, que ofereceu assimilação através da conversão (sagrada ou secular) àqueles fora de seu reino. A assimilação, ao invés, criou um espaço de acordo onde convertidos participaram em uma reunião de homogêneos - o que Rancière chama de polícia - para a negociação da distribuição de bens dentre uma 'partilha do sensível' baseada na regra de compartilhar o princípio que compõe o sensível, o que nós tomamos por ser a separação ontológica entre natureza e humanidade. Aquele que não partilham do princípio que compõe o sensível não pode, portanto, participar em sua partilha; eles não são, logo, eles não contam. A exclusão fundamental (a contagem daqueles que não contam) então articula o desacordo que é fundamental para a política que emerge como impossível quando confrontando a partilha do sensível: "política existe por meio do fato de uma magnitude que escapa a medição ordinária", e "é a introdução da incomensurabilidade no cerne da distribuição dos corpos falantes" - explica Rancière (1999:15,19). Um exemplo do que queremos dizer: os povos com que Ramos \& Sabatella trabalharam, que definem suas atividades políticas como "estar en la lucha", o que pode ser traduzido como a luta por seu mundo - seu sensível - contar, e para que eles contem a partir desse sensível.

Discordância, política nos temos de Rancière, pode não ter deixado de existir. Pode ter sobrevivido localmente, por exemplo, nos confrontos entre aqueles praticantes de 'paganismo' ou 'superstições' (i.e. aqueles se relacionando com outros além de seres humanos, e assim quebrando a Constituição Moderna) contra aqueles que julgaram essas práticas como indignas de existência (i.e. os executores da Constituição Moderna). Os artigos desta edição são sobre essas políticas locais, que atualmente alcançam além do local, e fazem visível o rompimento do princípio que rege e distribui o sensível. Essas políticas quebram a Constituição Moderna, quando interagem com o Estado, e através de práticas que vinculam nada menos que a reescrita da Constituição, como narra o trabalho de Schavelzon.

\section{COSMOPOLÍTICA: DESDE A GUERRA ATÉ A POLÍTICA}

Para construir nossa noção de cosmopolítica, pegamos emprestada (e ajustamos) a proposta cosmopolítica de Isabelle Stengers; ela a oferece para "desacelerar a razão e criar uma oportunidade de despertar uma consciência levemente diferente dos problemas e situações que nos mobilizam” (Stengers 2005:994). A proposta pretende provocar o pensamento; é diferente dos projetos que sabemos ir pelo que querem, e, mais frequente que não, o impõem. Como alternativa, afastando-se destes projetos, ela 'prefere não' seguir a imposição do usual e ouvir os murmúrios do que, em suas palavras, "não possui voz na política, não pode e talvez não queira possuir uma". Esses murmúrios insistem em manterem-se surdos à legitimidade da política moderna. A proposta cosmopolítica intervém nessa situação, propõe-se a agir 'na presença' daqueles que ignoram palavras impositivas, e não pretende saber o que sucederá desta intervenção. "Falar na presença de", significa aprender um discurso que não insiste no que é, e que, ao invés disso, é capaz de ser afetado pelo que não é - sem traduzir a si mesmo nisto. Falar na presença daquilo que insistentemente prefere não seguir a imposição incita o pensamento de um diferente tipo: não um que almeja explicar porque a imposição não é seguida, mas um que toma a insistência em ignorar seriamente ela, em outras palavras: o que se torna importante aqui 
não é a recusa da imposição, assim existindo enquanto negando-a, mas a afirmação de ser que é capaz de ignorar a imposição sem explicação, assim apresentando uma diferença que não está unicamente dentro da imposição - mas que também a escapa.

Estes artigos falam em tons cosmopolíticos: eles desaceleram a arena de acordo que foi fundamental à guerra silenciosa que exterminou mundos que insistentemente 'preferiam não estar' assimilados dentre o princípio que partilhou o sensível entre humanos e coisas, e os binarismos que seguiram e as hierarquias que promoveram, incluindo conhecimento e crença, tradição e modernidade, o Oeste e o resto. As práticas que estes artigos descrevem - relações com instituições modernas (o Estado, mercados heterogêneos, ONGs nacionais, fundações internacionais) que incluem outros além dos seres humanos - evidenciam momentos intrigantes de ruptura epistêmica com o mundo que conhecemos, e o revela tomando-se uma conexão parcial outra que a separação entre humanos e coisas. Essa transformação, mesmo que talvez efềmera e limitada a interações específicas, estressa o acordo que homogeneizou mundos e revela desacordos recalcitrantes que serão a matéria da cosmopolítica, uma conversa entre mundos divergentes com a capacidade de transformar uma relação de guerra em uma de política. Introduzir uma dimensão cosmopolítica (nos termos de Stenger) perturba o encontro do homogêneo e revela dentro dele a "parte daqueles que não possuem parte" (como diz Rancière) e assim a fundação equivocada da política moderna. Esse erro é que faz com que a parte que não possui parte, e é diverso; o erro que estes artigos revelam está localizado na Constituição Moderna, a prática de ambas, composta a parte que não possui parte, e estendida como um convite a contar na política moderna como não contando (cf. Legoas 2012).

O diálogo com Rancière, ou o ponto em que introduzimos o desacordo que as práticas políticas indígenas apresentam - e mesmo forçam - à política moderna, é talvez o ponto onde os artigos nesta edição desviam da proposta de Stenger, e onde a cosmopolítica emerge de nossas conversas com e sobre os indígenas andinos e pessoas amazônicas (humanas e outras além de humanas). Nestas conversas, a cosmopolítica não é uma noção especulativa, mas uma prática concreta. Embora não conceitualizemos a política como uma categoria antropológica universal, diferente de Stenger, não conceitualizamos política como "nossa” assinatura (cf. Stengers 2005: 996), ou que ela algum dia tenha sido. É algo que a Europa ofereceu os outros, de fato - mas quando estes outros encontraram a política, contaminaramna com excedentes que a Europa não poderia reconhecer. A Constituição Moderna nunca foi pura, mesmo que os políticos modernos teimosamente ajam como se fosse o caso. No que viria a ser a América Latina, tal constituição foi povoada pela cidade letrada e suas palavras - mas também era repleta com silêncios que o Estado não podia ouvir, e pontos cegos que não poderia ver. Mas que estavam lá. E aqui estamos falando sobre constituições especulativamente - mas também concretamente. O processo que resultou da recém editada constituição boliviana (e que Schavelzon descreve) revelou desacordo, o erro da conta como erro de cálculo - isto é, política nos termos de Rancière-e também os procedimentos pelos quais o desacordo tornou-se silêncio, o que, entretanto, não significou o fim do desacordo. Antes, o silêncio indicou locais onde o desacordo poderia continuar a surgir, onde não seria suprimido, onde condições para sua emergência fossem preservadas. A política moderna foi e continua a ser um evento histórico localizado em um complexo campo de batalha onde a proposta de construir um mundo alcançou um acordo que não era pleno 
- desacordo, ou as práticas daqueles que não tomam parte, estavam imiscuídas nele. Assim, a proposta política é inevitavelmente - "sempre já" como alguns gostam de dizer - contaminada pelos excessos de "nossos" termos. O "nós" que surge da rejeição da contaminação não cancela a contaminação ou purifica o "nós". Os “outros" são sempre parte de "nós" e vice-versa - mas nenhum é reduzível ao outro. Essa é a conexão parcial que mencionamos mais cedo nesta introdução, e nem políticas nem políticas indígenas escapam disto - antes, são entrelaçadas como tal: excedendo uma a outra em diferença radical, e participando na mesma.

A cosmopolítica indígena desafia o poder da política moderna a ignorar aqueles humanos e outros que não humanos que ela decide negar a existência. No entanto, e crucialmente importante, a cosmopolítica indígena não substitui o poder com um poder diferente: ela simplesmente relava o cosmos - práticas desconhecidas na diferença que provocam - e com esta revelação, pode propor a necessidade da atenção para os excessos da política moderna e seu modo de representação. Intrigantemente, as cosmologias políticas indígenas convidam a prática de pensamento fora das divisões entre natureza/cultura, sujeito/objeto, materialidade/espiritualidade, humano/animal, corpo/mente e todos os cognatos. Então também permitem uma análise que se mostra muito confortável sem a distinção entre o moderno e o não moderno, mas que ainda é capaz de evidenciar (uma prática, que não deita luz além do evidenciado!) diferenças radicais. Essas diferenças radicais são simplesmente aquelas que 'nos' surpreendem, ontologicamente e epistemologicamente, por que 'nós' não podemos reconhecê-las. E, na verdade, como as pessoas reagem a essas surpresas também pode indicar "nós", e "eles" - também conhecido como "o outro". A atitude que tende a explicar 'eles' como distanciados pode indicar o 'nós'; uma atitude de reconhecimento e curiosidade pode indicar 'eles'. Essa condição mais tarde pode adquirir historicamente a capacidade de ordenar um inclusivo “todos nós” que não apague as diferenças.

\section{OS ARTIGOS DESTA EDIÇÃO}

Sem a intenção - nem a possibilidade - de esgotar as múltiplas dimensões em que estes textos contribuem a uma reflexão sobre cosmopolíticas indígenas, os seguintes traços de interesse buscam sublinhar alguns de seus resultados mais relevantes. Começamos mencionando o trabalho de Ana Ramos \& María Emilia Sabatella sobre grupos mapuche-tehuelche atualizando uma antiga forma de parlamentos indígenas (futa trawün) onde se pensam estratégias de ação coletiva frente às políticas de Estado, projetos de mineração e esbulho de terras. Nestes espaços participam entidades reconhecidas como newen e as facas cerimoniais que as fazem presentes.

Os newen subtraem os espaços onde ocorre o parlamento Mapuche da divisão cultura/natureza, fazendo com que os recursos naturais deixem de serem recursos e naturais. Desde este novo espaço se convida o Estado ao diálogo e/ou as corporações privadas de mineração, desconcertando suas epistemologias e detendo a invasão de território mapuche. Os newen se revelam ali entidades gerenciais que permitem estes golpes epistêmicos às instancias de disputa com o Estado ou as empresas privadas, interpondo-se como elemento obrigatório nas negociações. 
Enquanto os newen preparam os Tehuelcheparaa "lucha", ou "política”, o texto de Guillermo Salas propõe um material importante para historicizar a agência dos apu-seres não humanos que participam dos mundos Quechua nos Andes ao Sul do Peru - em suas relações diretas com os atores da confrontação. O que salta em seu trabalho é que conta como estas relações mudam, de acordo com os processos em que ocorrem. Assim, seguindo as formas às quais os runakuna tem se relacionado historicamente com diferentes agentes (como o Estado, os hacendados e as empresas mineradoras), os apu haviam deixado de ser construídos como entidades subordinadas ao governo central, para ser seus negociadores diretos, os responsáveis pela ação das leis, e inclusive seus mais eficazes sabotadores. Mais recentemente, passaram a ser também de protetores da comunidade a mediadores em conflitos entre ela e as empresas mineradoras.

Também se poderia pensar que esta consideração das vozes sem importância na política só é possível hoje, quando elas irrompem no espaço público; sem embargo, o trabalho de Salas nos dá pistas concretas para rastrear a presença de imaginários políticos comunais que já influenciavam no dito cenário de relações, se não afetavam completamente as relações entre indígenas e patrões, Estado, ou empresas. Em definitivo, o texto propõe que as formas em que as montanhas foram entendidas e ocupadas pelos camponeses indígenas afetaram a aproximação dos últimos à esfera da política em diferentes momentos do último século.

William Martínez, utilizando seu trabalho de campo em um Resguardo Indígena Coconuco, nos Andes colombianos, segue uma controvérsia sobre a implantação de modelos de gestão empresarial de sistemas de água potável que serve de marco para apresentar o híbrido de natureza e cultura que é a água no citado resguardo. Martínez destaca principalmente como diferentes mundos são conectados por um sistema de água potável; mas que chegam a um encontro não somente através de tubos, mas também de contos sobre espíritos, produzindo assim um Puracé também híbrido que tanto trata com espíritos como da importância a materialidades. A conexão parcial em Puracé se faz notória como produto da larga convivência dos mundos modernos e não modernos que ali se encontram. As práticas de abastecimento de água se entendem como o resultado de certo pacto entre os atores que mantém um frágil equilíbrio ao desenvolvimento impulsionado pelo Estado moderno e a autonomia territorial indígena, com seus duendes, contos e espíritos.

Por outro lado, retomando a análise que faz Rosengren (2003) do movimento indígena, Juan Pablo Sarmiento descreve as formas pelas quais os Ashaninka do baixo Urubamba produzem sua subjetividade política. Por oposição ao fundamento etnicista que o ator atribui à prática de líderes e autoridades indígenas, sua análise se interessa pelos princípios relacionais que sustentam outras vias (coletivas e simétricas) pelas quais o Ashaninka se constitui como sujeito político. $\mathrm{O}$ conteúdo concreto dos ditos princípios está dado por princípios do viver bem e de serem pessoas produtivas - no sentido Ashaninka- e integradas ao grupo.

Dado que as práticas e saberes Ashaninka estão fundados tanto em práticas etnopolíticas (que o autor localiza nas relações com o Estado) como práticas relacionais (que existem nas relações comunais), da análise de Sarmiento pode se concluir que a estratégia política Ashaninka faz uso de ambos os argumentos: por um lado, o recurso a porções 'permitidas' do argumento etnopolítico ocorre quando os grupos se veem pressionados por interesses externos como 
os de ONGs e do Estado; por outro lado, esse vetor se contraria com o uso do argumento relacional, que aponta no sentido de evitar a criação de diferenças entre semelhantes. A partir daí, o artigo se concentra basicamente nos sentidos de igualdade e autonomia presentes nos argumentos relacionais. A simetria contida neles seria a que permite aos Ashaninka exercer uma agência que desafia as formas assimétricas de intervenção que o Estado e as ONGs interpõem através de hierarquias que excluem (ignoram, distorcem, mal interpretam, ou desacreditam) os interesses e formas de expressão indígenas.

Enquanto Sarmiento ilustra um caso de oposição à intervenção de agentes externos à comunidade, por outro lado, Cayón ressalta as possibilidades que os líderes e autoridades Makuna del Vaués desenvolvem, quando se trata de articular seu mundo com aquele do Estado colombiano. Por exemplo, se inscrevem geracionalmente a processos de reconhecimento que, de outras formas, lhes seriam impostos pelo Estado. Dentre esse marco, elaboram planos de desenvolvimento (em forma de "planos de vida") fazendo visíveis neles algumas práticas que o Estado não tem a capacidade de conhecer porque são ontológica e epistemologicamente distantes - e, portanto tampouco pode reconhecer. Os planos de vida se convertem assim para eles em instrumentos de busca da inteligibilidade e de demanda profunda por autonomia.

Cayón enfatiza a forma em que organizações indígenas podem se mostrar permeáveis ao contato com o Estado, buscando manter seus objetivos coletivos em meio a processos impositivos que sabem traduzir toda diferença à linguagem de uma governabilidade multicultural liberal. Mas em contextos como esse, a busca de inteligibilidade tem seus limites. Cayón sublinha assim as diferenças entre as práticas indígenas capazes de articulação e que manifestam perícia traditiva e agentes de estado que impõem regras e que consideram atores não humanos e argumentos não ocidentais como "crenças", as quais se honra apenas se não se constroem como alternativa epistêmica à eficiência produtiva, ao crescimento econômico, ao desenvolvimento sustentável, ou inclusive à ecologia.

Finalmente, Salvador Schavelzon situa sua discussão em um cenário onde o indígena alcança o âmbito mais 'oficial' da política de Estado. Ele analisa a diferença epistêmica que dividiu indígenas, socialistas, liberais e conservadores em torno da produção de uma nova constituição para a Bolívia, durante o primeiro governo de Evo Morales. Seu estudo dá conta da dificuldade de fazer valer novas ordens políticas provenientes de práticas indígenas, em um campo onde ainda prevalecem lógicas modernas tanto liberais como conservadoras. Foi nessa tensão entre os indígenas e a aliança de liberais e conservadores que a Constituição foi elaborada. Os primeiros acusavam os segundos de fazer eco de ressentimentos sociais antigos e pleitear um fundamentalismo arcaizante. Na Assembleia reinavam duas ideias opostas: por um lado a que pleiteava que a comunidade e suas formas particulares de política não eram algo que valeria a pena tomar em conta para elaborar uma constituição, e por outro, a ideia de que a Bolívia - o país inteiro - estava sulcada de indigeneidade.

Schavelzon revela que, ante a fricção e impossibilidade de tradução entre mundos que caracterizou a polêmica constituinte, foi necessário aplicar uma estratégia especial para que os mundos indígenas pudessem irromper e fazer-se valer em um meio que buscava incluí-los excluindo-os. A estratégia foi o solapamento, sua auto suspenção, 
a apresentação de noções indefinidas que escondiam os silêncios. Não mencionar um ponto, ou não abordá-lo, se mostrou mais estratégico que resignar-se a inclui-lo de maneira distorcida. Assim, o pleito de um quadro incompleto e aberto - mais que a inserção específica e delimitada - foi o que caracterizou a difícil tarefa de abrir caminho através do constituído, na Bolívia.

No conjunto, os seis trabalhos partem de relações entre mundos que separam natureza e cultura, e mundos que não fazem essa separação; ou seja, apresentam relações entre mundos com composições naturais-culturais específicas (Poirier 2008). Em seguida, elementos como flautas de yurupari, Pachamama, Bem Viver, duendes, newen e apu com tubos, partidos políticos e Assembleias Constituintes; e a partir da mistura - que não sintetiza as diferenças fazendoas desaparecer um uma formação 'mestiça' - os autores assumem a tarefa de apreender a política indígena em seu encontro com os mundos e práticas com que se vinculam. Descrevem o como da conexão parcial, localizando a ideia de 'cosmos' na diferença que tanto separa as práticas não modernas das predominantemente modernas, como também as associa simbioticamente - mesmo quando a relação seja 'forçada' pelo Estado e suas instituições políticas: um projeto de desenvolvimento, uma assembleia constituinte, um partido político de massas, processos estatais de reconhecimento, negociações mineradoras.

A análise também dá conta de estratégias políticas produtos de uma intencionalidade refletida e acumulada por anos, ou como recurso pragmático diante de circunstâncias inesperadas. Silêncios, solapamentos, adesões estratégicas, encontros e performances públicas, gestos que podem significar um ponto de suspensão da política formal, ou de fricção entre diferenças fundamentais. As estratégias cosmopolíticas aparecem assim como expressão de uma gestão indígena do possível. Nos atentam, ademais, à eventualidade de escapar à sentença de que "visões de mundo podem conceber de tudo, exceto visões de mundo alternativas" (Eco 1984) . A interpelação simétrica entre mundos em desacordo fundamental teria assim a capacidade de mostrar caminhos até a saída deste impasse, ainda que contenha também o risco inescapável de produzir o contrário.

Finalmente, levar a sério as práticas indígenas (de la Cadena 2010, Ingold 2000, Povinelli 1995) não quer dizer deixar de observar os outros atores do encontro contemporâneo: corporações e governos desenvolvimentistas. Diante seu tecnicismo que sustenta que o ator local não pode compreender a complexidade dos problemas (cf. De Echave \& Diez 2013:114), o que se apresenta como simples exigência de "claridade" na redação de uma Constituição (como nos conta Schavelzon), a negociação da possibilidade de ser - que implica a cosmopolítica - seguirá derivando muitas vezes na política de guerra entre inimigos. A convicção absoluta da legitimidade destes discursos produz então a desqualificação das presenças indígenas e toma de soslaio as demandas mais profundas que elas portam, seus newen, seus silêncios, suas montanhas. Nossos relatos - porque é isto que são: relatos - teriam algo a dizer também sobre esta desvantagem atualizada. 


\section{BIBLIOGRAFIA}

De la Cadena, Marisol (2010) Indigenous cosmopolitics in the Andes: Conceptual reflections beyond "Politics". Cultural Anthropology 25(2):334-370.

De Echave, José \& Alejandro Diez(2013) Más allá de Conga. Lima: Red Peruana por una Globalización con Equidad.

Eco, Umberto (1984) Semiotics and the Philosophy of Language. Bloomington, University of Indiana Press.

Haraway, Donna (1991) Simians, cyborgs, and women: The reinvention of nature. New York: Routledge.

Ingold, Tim (2000) The Perception of the Environment: Essays in livelihood, dwelling, and skill. Londres \& New York: Routledge.

Latour, Bruno (1991) Nous n'avons jamais été modernes. Essai d'anthropologie symétrique. Paris: La Découverte.

Law, John (2004) And if the global were small and non-coherent? Method, complexity and the Baroque. Society and Space 22:13-26.

Legoas, Jorge (2012) «La inclusión asimétrica: Trasfondo de la participación ciudadana en el Sur andino peruano», pp. 107-134. In S. Rousseau \& V.Armony (eds.) Diversidad cultural, desigualdades y democratización en América Latina. Bruxelles: Peter Lang.

Poirier, Sylvie (2008) Reflections in indigenous cosmopolitics-poetics. Anthropologica 50(1):75-85.

Povinelli, Elizabeth (1995) Do rocks listen?The cultural politics of apprehending Australian aboriginal labor. American Anthropologist 97(3):505-518.

Rancière, Jacques (1999) Disagreement: Politics and Philosophy. Minneapolis: University of Minnesota Press.

Rosengren, Dan (2003) The collective self and the ethnopolitical movement: 'Rhizomes' and 'taproots' in the Amazon. Identities: Global Studies in Culture and Power, 10(2):221-240.

Schmitt, Carl (1996) The Concept of the Political. Chicago: University of Chicago Press.

Stengers, Isabelle (2005) «The Cosmopolitical Proposal», pp. 994-1004. In B. Latour \& P. Weibel (eds.) Making Things Public: Atmospheres of Democracy. Cambridge, MA: MIT Press.

Strathern, Marilyn (2004) Partial connections. New York: AltaMira.

Viveiros de Castro, Eduardo (2004) Perspectival anthropology and the method of controlled equivocation. Tipití, Journal of the Society for the Anthropology of Lowland South America 2(1):3-22. 